\title{
essonâncias \\ As ciladas da Imprensa. Sobre 0 artigo de Marta Severo: A imagem da mulher em Revistas Femininas
}

inco pontos relevantes são criticados, pelo autor, a partir da análise do artigo de Marta Severo, publicado nos $n^{\circ} s 1 / 2 / 3$, do volume 15 desta Revista: separação entre mundo público e privado; cultura versus natureza; quem são as leitoras das revistas; o estudo restrito aos editoriais e o papel dos meios de comunicação.

\section{André Pires \\ Mestrado em Antropologia Social UNICAMP.}

Severo inicia seu artigo opondo dois tipos de imagens de mulheres. O primeiro, mais negativo, é marcado por uma separaçăo entre mundo privado e mundo público, no qual as mulheres estariam confinadas ao mundo privado, aos papéis de mãe, dona de casa, e, portanto, impossibilitadas de uma vivência mais ampla no domínio público. O segundo tipo de imagem, mais positivo, aparece recentemente em virtude das transformações econômicas, sociais e culturais. É a imagem de uma mulher que está revendo os papéis tradicionais femininos, na medida em que participa mais ativamente do mundo público, até então um espaço predominantemente masculino, redefine os relacionamentos com os homens e ocupa e reivindica poder, prazer, liberdade, dignidade e direitos.

Embora exista esta nova mulher, os processos de socialização, especificamente, a educação - formal e informal -

reproduzir o papel da mulher voltada
CARLOS MOURA

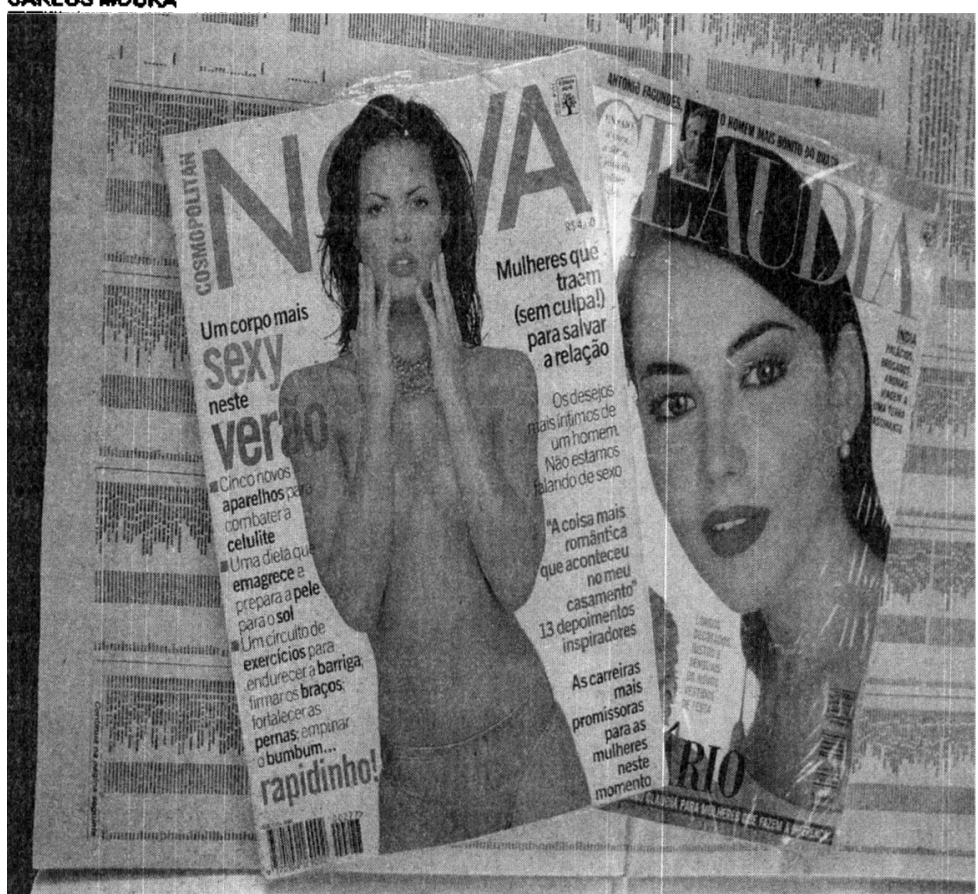
exclusivamente para o mundo privado. Especial ênfase é dada ao papel da educação tradicional na formação deste estereótipo de mulher, uma vez que, do ponto de vista psicanalítico, a estruturaçăo da personalidade do indivíduo dá-se nos primeiros anos de vida.

Ao constatar um aparente descompasso entre, por um lado, uma imagem de mulher que rompe as barreiras do domínio privado e conquista o mundo público, e por outro, uma imagem "estereotipada" da mulher condenada ao domínio privado, Severo expõe seu objetivo que é pesquisar: "se estes elementos de educação tradicional ainda podem ser encontrados em revistas femininas, aparentemente conservadoras, bem como em revistas femininas que se declaram mais comprometidas com um papel de mulher arrojado e moderno" (Severo, M. 1996, p. 23).

A minha intenção é mostrar como Severo, apesar de partir de um instigante objetivo, compromete sua reflexão ao não problematizar suas hipóteses e acaba caindo no que eu chamo de "armadilha da imprensa". Gostaria de tecer algumas considerações sobre o seu artigo em termos de cinco críticas.

I)- Começarei pelas suas hipóteses. A separação entre mundo público e mundo privado, proposta pela autora e tão importante na definição dos papéis das mulheres, aparece de forma ambígua em seu texto. O mundo público é definido como "mundo 


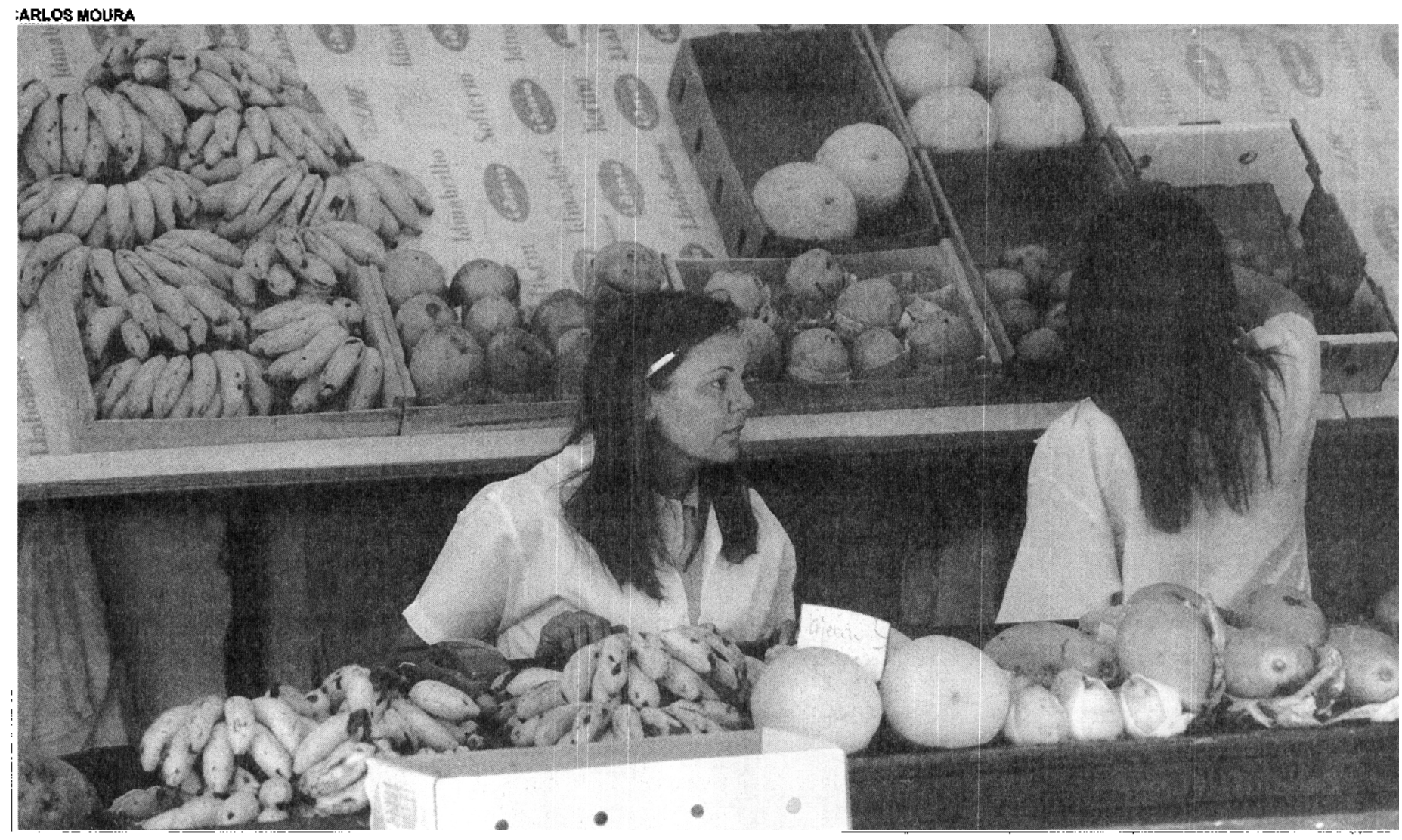

nais amplo da participação pública" (apud Friedar 1963), embora em alguns nomentos ele seja entendido como sento somente o espaço da carreira profisinonal. Além de uma certa imprecisăo 1a đefinição dos limites e do conteúdo to que a autora entende como "mundo amplo da participação pública", a maneira como ela opera a separação entre público e privado năo coteja algumas reflexōes que me parecem fundamentais na sua tentativa de romper com a "pseudodicotomia entre ser esposa/ mãe/dona de casa ou ser profissional" (Severo, 1996 p.22).

No meu entender, Severo parte de uma noção de senso comum a respeito de mundo público e mundo privado. Com efeito, sua abordagem deixa de lado o debate sobre a questão que conceitua, historia e aponta as conseqüências da separação entre mundo público e privado nas sociedade ocidentais. Vários autores têm procurado caracterizar esta separação.

Ariès (Ariès, P. 1991) procura entender as transformações que explicam a mudança de um tipo de organização social, em que não havia uma distinção clara entre mundo público e privado final da Idade Média -, para um em que há uma separação entre eles, século XIX, onde o espaço público é ocupado pelo Estado e o privado ocupado pela família. Para Ariès, este processo, que abrange todo o período moderno clássico, é marcado mais por transformaçōes ao nível das "mentalidades mais profundas", o que torna seu trabalho diferente da maneira pela qual a historiografia clássíca entende este período - visto como uma sucessão de acontecimentos, marcados por uma visão de progresso, pela qual a sociedade medieval se transforma em sociedade moderna -. A despeito de considerações historiográficas, podemos dizer que para Ariès, já no final do século XVIII, havia a separação entre mundo público e privado, cada um com sua autonomia, e que o Estado ocupa-se do público e a família do privado.

Sennett (Sennett, R. 1993) também considera a formaçāo de duas esferas distintas, a pública e a privada, como sendo produto de transformações históricas. No entanto, sua análise sugere que as recentes transformações, sobretudo dos séculos XIX e XX, acabam por dissolver o espaço público, entendido como o espaço da sociabilidade, tão importante e tão valorizado pelo autor. Sennett utiliza-se de uma análise que tem por referência o século XVIII, em que o público e o privado, já constituí- dos como esferas autônomas da vida social, têm uma função complementar. A partir do século XIX, uma série de transformações iniciam-se até chegar no século $\mathrm{XX}$, século em que o espaço público se esgota, uma vez que é invadido pelos sentimentos pessoais, típicos de uma personalidade narcísea do século $X X$. É interessante observar que, no rol de transformações responsáveis pelo fim do espaço público, o autor aponta para 0 advento da moderna Psicologia, em especial da Psicanálise, fundada na crença de um entendimento dos processos íntimos de um eu sui generis, liberto de idéias transcendentais de mau e de pecado, que acaba tendo vastas consequêencias sociais: a formação de uma visão intimista de sociedade. O subtítulo da edição em português, As Tiranias da Intimidade, mostra que para Sennett o espaço público foi invadido pela personalidade narcísea típica do século XX.

Finalmente, Giddens (GIDDENS, A. 1992) vê com melhores olhos a formação da intimidade, presente nas sociedades ocidentais contemporâneas. Neste sentido, Giddens rompe com uma dicotomia rígida entre esfera pública e privada, uma vez que as transformações da intimidade, com a emergência do que o autor chama de "relacionamentos pu- 
ros" sinalizam para mudanças emancipadoras da vida social. "A transformação da intimidade poderia ser uma influência subversiva sobre as instituiçóes modernas como um todo. Um mundo social em que a realização emocional substituisse a maximizaçăo do crescimento econômico seria muito diferente daquele que conhecemos hoje. As mudanças que atualmente afetam a sexualidade são, na verdade, revolucionárias e muito profundas". (GIDDENS, A. 1992, p. 11).

Neste sentido, a pró. pria separação entre "mundo doméstico" e "mundo externo ao lar" proposta pela autora parece-me questionável. A sexualidade, por exemplo, é colocada como fazendo parte do mundo doméstico. Com efeito, vimos que para Giddens esta separação não é desejável uma vez que, nas sociedades contemporâneas, a sexualidade, assim como outras categorias apontadas por Severo como cuidados pessoais, saúde, beleza, etc., são geridas pelo que o autor chama de "sistemas abstratos" que passam a ser fundamentais na formaçăo da identida. de do eu. "Hoje em dia, o eu é para todos um projeto reflexivo - uma interrogação mais ou menos contínua do passado, do presente e do futuro. É um projeto conduzido em meio a uma profusão de recursos reflexivos: terapia e manuais de auto-ajuda de todos os tipos, programas de televisão e artigos de revista" (GIDDENS, A. 1992, p. 41). Portanto, a sexualidade, só para ficar neste exemplo, não se ređuz somente

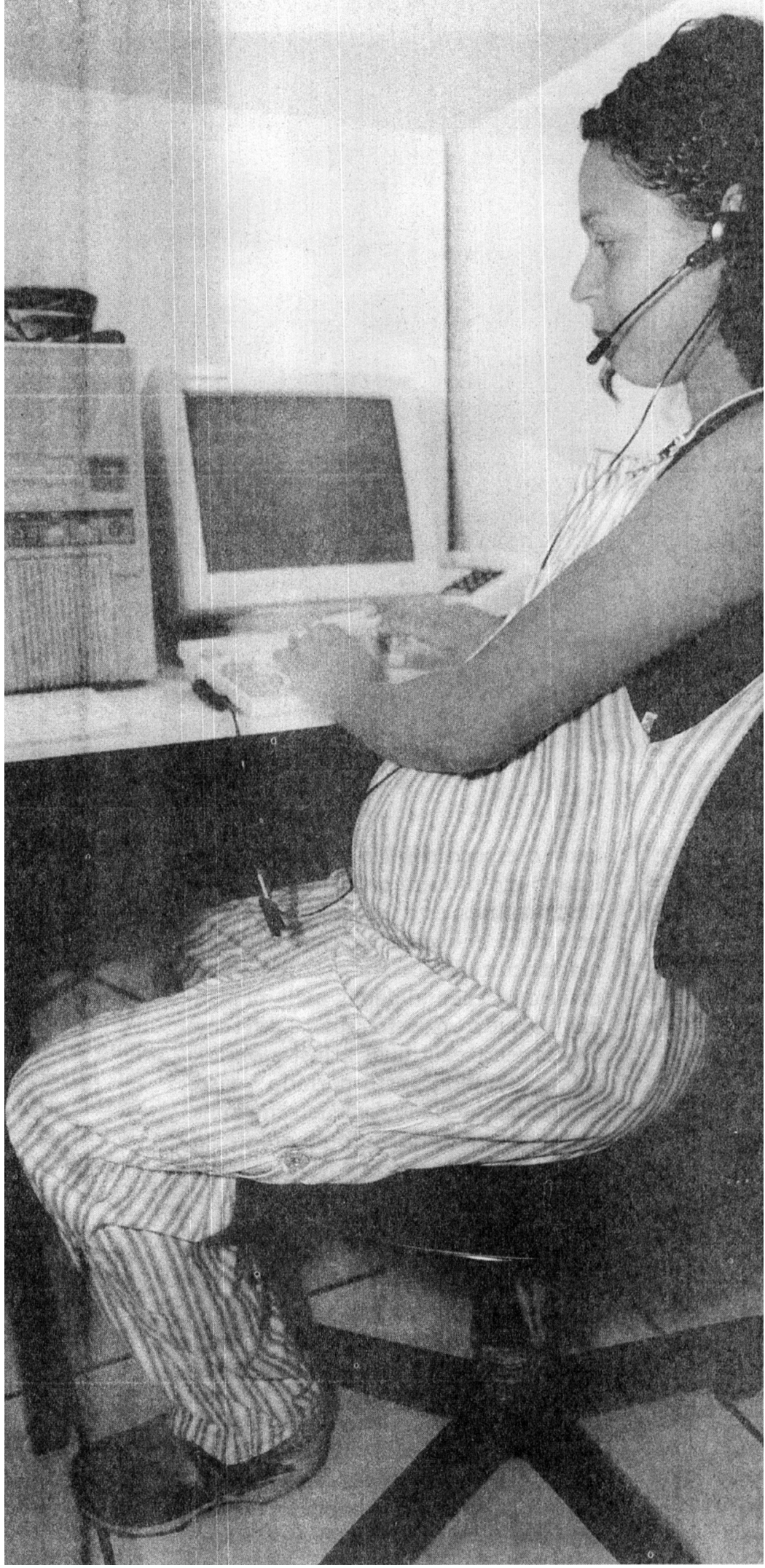

cos, especializados, tal como comportamentos adequados sugeridos pelas revistas. Ademais, o movimento feminista, de uma maneira geral, lutou para mostrar que aquilo que seria considerado privado, violência contra a mulher em casa, por exemplo, também é um assunto público.

II)- Outro ponto que me parece pouco trabalhado pela autora é a questão da transmissão da cultura, em especial, dos papéis sexuais tidos como adequados. Embora seja louvável a sua intenção problematizar $o$ aspecto de algoz que as mulheres atribuem aos homens, a maneira como a autora coloca a produção das diferenças, entre homens e mulheres, não está suficientemente clara.

Neste sentido, Stolcke (STOLCKE, V. 1991) oferece contribuiçöes mais interessantes ao mostrar que, num primeiro momento, a formação da categoria gênero, assim como da categoria etnicidade, representou uma tentativa de libertar o social de explicações que tinham por base referência a processos naturais biologizantes dando autonomia à esfera do social-cultural. No entanto, Stolcke vai além e desafia a perspectiva đualista, própria do senso comum ocidental, em separar natureza e cultura como dois aspectos distintos da experiência humana. Em seu artigo, Stolcke mostra que mesmo os fatos tidos como naturais são decorrentes de pressupostos culturais próprios de situ- ao domínio privado, "doméstico", mas é um elemento da formação da identidade reflexiva do eu que passa a ser constituído em meio a sistemas técniações históricas das sociedades ocidentais. Por exemplo, na definição dos sexos, tido como algo natural, ênfase é dada ao aparelho reprodutor quando há 


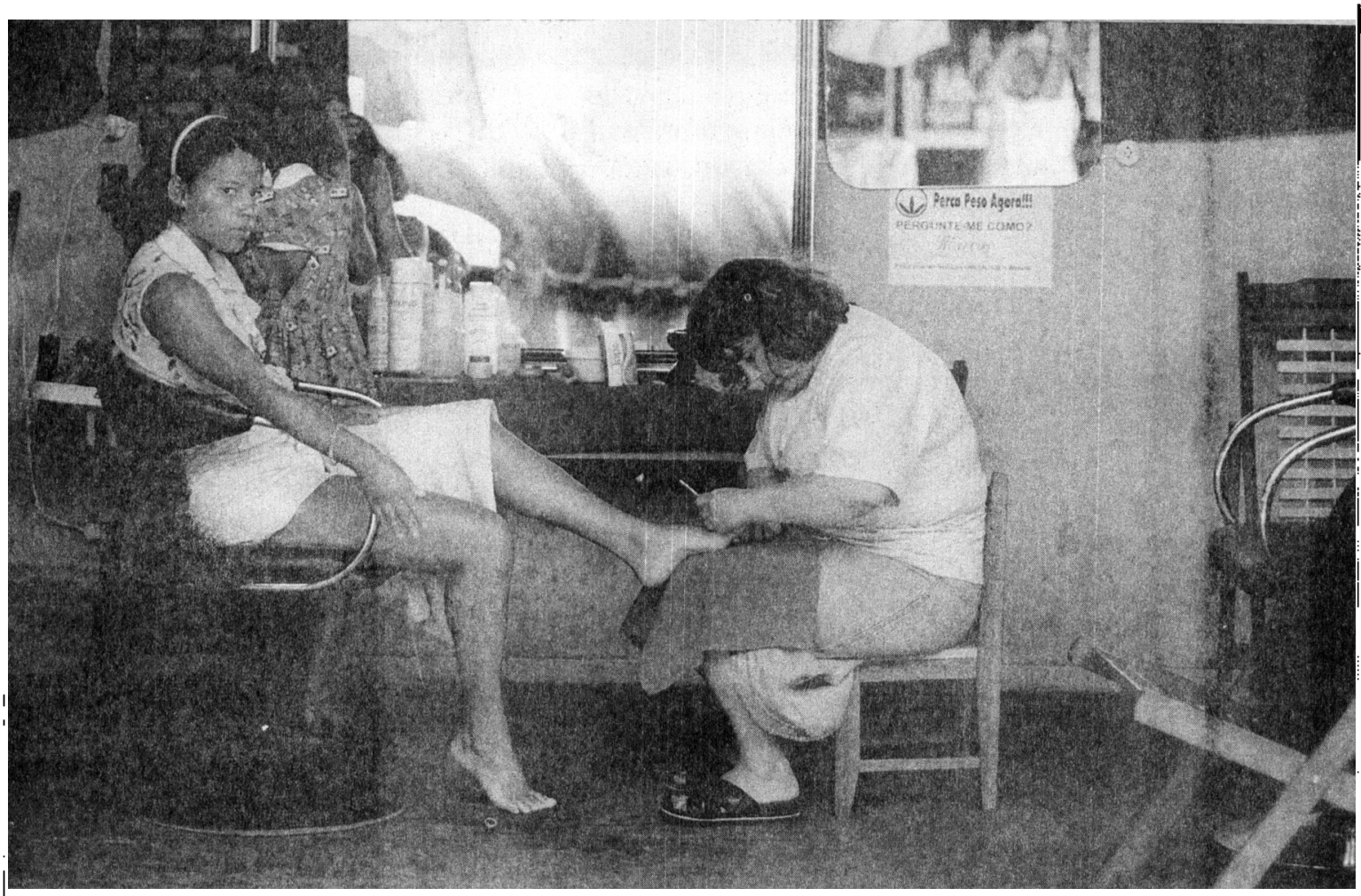

vero, que mostram o perfil dos leitores de Cláudia e Nova nāo tão diverso como o apontado pela autora. Primeiro, a leitora de Cláudia não é tão mais velha, em relação a Nova, como supōe Severo. A maioria das leitoras de Cláudia - $54 \%$ -, em 1990, estava entre os 15 e 29 anos.

Ademais, é possível que durante o período analisado, dez anos, tenha havido mudanças no perfil dos leitores que não foram sequer sugeridas pela autora. Com efeito, as diferenças entre

uma série de outras diferenças que poderiam ser admissíveis, como por exemplo: peso corporal (ver também BUTLER, J. 1992). Uma vez que mesmo os processos tidos como naturais tèm raízes culturais e que, portanto, natureza e cultura não constituem dois reinos separados da natureza humana, as colocações de Severo podem ser problematizadas já que elas insistem na separação entre processos culturais e biológicos. "Entretanto, ao admitir-se que grande parte das diferenças se deu por questões culturajs, e não apenas biológicas, cabe-nos observar como é transmitida a cultura". (SEVERO, M. 1996 , p. 23).

III) - Vejamos como a autora seleciona as revistas que são objeto de sua aná- lise. Severo escolhe os editoriais das revistas Cláudia e Nova, entre 1981 a 1990. A escolha de duas revistas deu-se, segundo a autora, porque elas apresentam perfil de leitores diferentes. Ambas tểm como público-alvo mulheres de classe média e alta; cuntudo, Cláudia dirigese "a mulheres cronologicamente mais maduras, geralmente casadas, mães e que se dedicam ao lar", enquanto que Nova "pretende representar a voz de um tipo de mulher das mesmas classes sociais, mas mais jovens, geralmente solteira, ou divorciada, e que trabalha fora de casa”.

Severo apresenta estas distinções sem mostrar dados dos leitores das revistas. Disponho de dados de 1990 , último ano do universo de pesquisa de Se-

\begin{tabular}{|l|c|c|c|}
\hline Leitoras & $15-19$ anos & $20-29$ anos & $30-39$ anos \\
\hline Cláudia & $18 \%$ & $36 \%$ & $22 \%$ \\
\hline Nova & $23 \%$ & $42 \%$ & $19 \%$ \\
\hline
\end{tabular}

Fonte: XXII Estudos Marplan/90 - 9 mercados

Segundo o total de mulheres leitoras, das duas revistas, que trabalham também não é tão diferente.

\begin{tabular}{|l|c|c|c|}
\hline Revista & $\begin{array}{c}\text { Mulheres que } \\
\text { trabalham }\end{array}$ & $\begin{array}{c}\text { Donas de } \\
\text { casa }\end{array}$ & $\begin{array}{c}\text { Donas de casa que } \\
\text { trabalham }\end{array}$ \\
\hline Cláudia & $50 \%$ & $48 \%$ & $22 \%$ \\
\hline Nova & $57 \%$ & $35 \%$ & $17 \%$ \\
\hline
\end{tabular}

as leitoras de Cláudia e Nova, a meu ver, devem ser procuradas menos no perfil das leitoras e mais no conteúdo destas revistas.

IV)- Uma vez escolhido o material, Severo parte para a análise dos editoriais destas revistas. Por que somente os editoriais? Será que eles são, como diz a autora, a parte mais nobre de uma publicação? Será que não é possível encontrar a opinião da revista, ou dos seus editores, em matérias, reportagens ou entrevistas? Será que os textos da revista, exceto o editorial, são imparciais? Fica a pergunta.

Severo não deixa claro, em seu texto, a quantidade de editoriais lidos que fundamentam de seu artigo. Quando faz o quadro-resumo das categorias e subcategorias referente aos temas destes editoriais, Severo descuida-se de passar para o leitor informaçōes fundamentais. Suponhamos que aceitasse a divisão entre "mundo externo" e "mundo doméstico" proposta pela autora e já questionada no item I deste comentário. Mesmo assim, o leitor ficaria privado de saber qual o espaço que a categoria "mundo doméstico" ocupa nos editoriais da revista Cláudia em comparação com o espaço ocupado pela mesma categoria em Nova? Do total de editoriais analisados, qual a porcentagem que ocupa, por exemplo, a categoria "mundo externo"? 
V)- A maneira como Severo trata o papel dos meios de comunicação em nossa sociedade, também parece-me um ponto a ser questionado em seu trabalho. "As revistas são uma forma popular de distribuir informações atualizadas $e$ cultura, pois os livros, na maioria das vezes, năo atingem o grande público". (SEVERO, M. 1996, p.25).

Neste sentido, retomo as minhas colocações iniciąis para tratar do que eu chamo de a "cilada da imprensa". Severo entende que as revistas, e por isso escolhe este objeto de pesquisa, são um material privilegiado para refletir sobre os valores, costumes e comportamentos de uma sociedade. A imprensa, portanto, é vista como um órgão que distribui as informações disponíveis em uma determinada sociedade e analisar o material da imprensa é poder chegar aos valores e comportamentos vigentes em uma determinada época. Qual era a sua intenção, senão a de mostrar que os editoriais ainda mantêm a imagem, presente na nossa sociedade, da mulher voltada ao lar e a família, fruto de um processo de socialização que molda as nossas percepções acerca do papel feminino.

Mas será que a imprensa somente desempenha o papel de reprodutor de informações, valores e comportamentos da nossa sociedade? Será que a imprensa também não constrói e desconstrói contextos? (WISNIK, J. 1992). Tratar os meios de comunicação da maneira como faz Severo é, na minha opiniąo, năo ver o papel ativo que eles desempenham na vida social contemporânea é por isso, cair na "cilada da imprensa".

Post-scriptum: Gostaria de agradecer os comentários e as sugestöes dadas pela Profa. Dra. Guita Grin Debert a este texto.

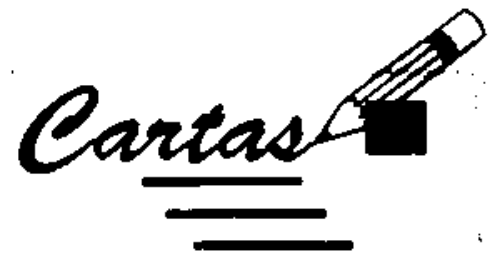

- "Há muito tempo venho pensando em escrever para essa Co. missāo com a intençāo de protestar contra a congérie de tolices que a revista vem produzindo generosamente... Refiro-me, agora, apenas ao último número dessa "Psicologia: Ciência e Profissáo" e nāo a todos os textos nela publicados, mas apenas a dois. Em primeiro lugar, há nela um artigo em que a autora faz uma terrivel confusão entre gênero gramatical das palauras e gênero biológico dos organismos vivos. São duas coisas absolutamente diversas. Por que porta é feminino e portảo é masculino? Será que porta tem vagina e portão possui pênis? Citar o dicionário Aurélio na questão dos gêneros macho e fêmea é totalmente risivel e cientificamente uma bobagem. Em segundo lugar, aqueles disparates a respeito de Nietzsche... Como é possível que alguém aceite para publicação todas aquelas fantasias sobre Apolo e Dionísio, o Eterno Retorno, etc., etc.? Será que a autora leu algum texto desse filósofo que tanto odiou os alemães e os cristäos?..."

Psicólogo Gualdino Pedro de Couto/CRP 07/0026

OBSERVAÇĀO: O leitor refere-se aos números 1, 2, 3/95 da revista, cujo tema foi Imagem de Mulher.

\section{Nota da Comissão Editorial:}

Estamos reorganizando a seção CARTAS, a partir desta edição. $O$ envio das mesmas não significa sua necessária publicação. As cartas serão apreciadas pela Comissão Editorial que decidirá sobre sua publicação, total ou parcial, ou não publicação.

Contamos com a colaboração dos psicólogos. SRTVN, Q. 702, Edifício Brasília Rádio Center, Sala 4024-A. Brasília, of Cep 70719-900. 